\title{
Effect of Arbuscular Mycorrhizal inoculation on Biomass, Nutrient Uptake, Root Infectivity and Soil Colonization of Papaya (Carica papaya L.) Seedlings
}

\author{
D.K. Chebet*1 , F. K. Wanzala ${ }^{2}$ and L.S. Wamocho ${ }^{3}$
}

\author{
${ }^{1}$ Seeds, Crops and Horticulture Science Department, University of Eldoret, \\ ${ }^{2}$ Horticulture Department, Jomo Kenyatta University of Agriculture and Technology, Kenya \\ ${ }^{3}$ Department of Agriculture, Masinde Muliro University of Science and Technology, Kenya \\ *Corresponding author
}

\begin{abstract}
The effect of Arbuscular mycorrhiza (AM) fungi on biomass accumulation, nutrient uptake, mycorrhizal root infectivity and soil colonization was determined in Papaya (Carica papaya) seedlings raised under four phosphorus regimes in sand culture and also in 1:1 sand/soil media under sterile and unsterile conditions. Inoculation with AM fungi increased the plant height, leaf number, and stem girth in relation to uninoculated seedlings grown under equivalent $P$ concentrations. An increase in plant height, leaf number and stem girth also occurred in both inoculated sterile and un-sterile 1:1 sand/soil media in relation to uninoculated sterile and unsterile media. Arbuscular mycorrhiza also increased the leaf area and the root, leaf and stem fresh and dry weights and also caused an increase in the uptake of phosphorus and potassium in the leaf tissues. It also favoured mycorrhizal infectivity of roots, soil mycorrhizal spore colonization and increased the root absorptive surface area. This study indicates that AM fungi improves the capacity of papaya seedlings to absorb and utilize plant nutrients possibly by increasing the effective root surface area from which available form of nutrients are absorbed and also by increasing access of roots by bridging the depletion zones. As a low cost technology, arbuscular mycorrhizal inoculation is recommended as part of the regular practise into nursery media used for papaya seedling propagation.
\end{abstract}

Keywords—passion fruit, papaya, phosphorus, potassium.

\section{INTRODUCTION}

A major problem that faces fruit as well as other agricultural sectors in many tropical countries is the gradual and adverse change in the soil biological, physical and chemical characteristics. Major soil factors that constraint crop production include soil moisture stress, low nutrient capital, soil erosion and degradation, low $\mathrm{pH}$ with aluminum toxicity, high phosphorus fixation, low levels of organic matter and loss of soil biodiversity (Cardoso and Kuyper, 2006). Other adverse changes that have occurred include increased natural resource degradation and a build-up of harmful microbes and pests paralleled by a reduction of beneficial soil organisms. Land degradation and soil fertility depletion are considered the major threats to food security and natural resource conservation in sub-Saharan Africa (Cardoso and Kuyper, 2006, Chebet et al., 2020).

Under tropical conditions, AM fungi could be highly beneficial to perennial crops, which require nursery production before transplanting to the field. However, although arbuscular mycorrhiza associations, and their fungal propagules (spores, mycelium and infected roots) are widespread in the tropics (Sieverding, 1991), propagules can be lost or their species changed through site disturbance, inhibiting the renewal of vegetation cover, or changing its composition (Mason and Wilson, 1994). In fruit orchards in Kenya, the AM fungal spores and the mycorrhizal infection of fruit tree roots are low (Wamocho, 1998). Likewise, naturally occurring mycorrhiza formation in fruit/tree 
nurseries are sparse, even in unsterilized soils, leading to poorly mycorrhizal or potentially-poorly performing seedlings being transplanted (Michelson, 1992).

Mycorrhizal spores can be found in a wide diversity of habitats in the tropics. For example, studies in Lake Victoria basin in Kenya showed significant differences in richness and relative abundance of indigenous arbuscular mycorrhizal fungi. Undisturbed soils (Lambwe Valley) had the highest total spore count (12.59 per gram root dry weight) while farmed areas (represented by Kibos) had the lowest (4.23 per gram root dry weight) (Othira et al. 2014). Glomus was the dominant AMF in all soils $(49.74 \%)$ followed by Scutellospora (29.60\%) and Gigaspora (15.80\%) (Othira et al. 2014). Lambwe soils also showed a higher degree of AMF diversity $(\mathrm{H}=1.21)$ while Njoro had the least diversity $(\mathrm{H}=1.08)$ (Othira et al. 2014).

In Haryana Agricultural University Hisar, India (longitude of $75^{\circ} 46^{\prime}$ E), the number of spores per 50 grams of soil ranged from 0 to 925 in spring-summer season crops and 25 to 1150 in winter season crops (Bansal et al., 2012). Maximum AM fungi spores were found in the rhizospheric soil of sorghum with 925 spores per 50 gram of soil and minimum in cotton with 25 spores per 50 gram of soil, while no spores were found in pigeon pea and urdbean field soils (Bansal et al., 2012).

Limited research have been undertaken on the role of AM fungi on the growth, nutrient uptake and root infectivity of tropical fruit species, unlike in temperate fruit species. To meet this objective, this experiment was undertaken to determine the role of AM fungi in papaya (Carica papaya var Mountain) in Kenya.

\section{MATERIALS AND METHODS}

\section{Treatments and experimental design}

Papaya seeds were germinated in sterile sand and uniform seedlings selected and transplanted to polythene pots $(20 \mathrm{~cm}$ in diameter and $25 \mathrm{~cm}$ depth) in a polyethylene-covered greenhouse. An experiment was also laid out in low nutrient soil and sand media $(1: 1 \mathrm{vol} / \mathrm{vol})$ as a $2 \times 2$ factorial design consisting of 2 kinds of AM inoculation (AM inoculated and un-inoculated) and 2 media conditions (sterile and nonsterile) with 6 replicates per treatment. The AM inoculum contained approximately 200 spores of a mixture of Glomus caledonium, G. etunicatum, Gigaspora magarita and Scutellospora sp (Plantworks Inc., UK). To ensure uniformity, similar quantities of autoclaved inoculum were added to the non-mycorrhizal pots.

\section{Plant growth measurements}

Weekly measurements were taken on plant height, leaf number and stem girth, starting two weeks after inoculation.

\section{Biomass and nutrient analysis}

At seedling harvest, measurements were taken on leaf area and leaf, stem and root fresh and dry weights. Oven-dried shoots were then ground and 1 gram from each seedling weighed and dry-ashed by heating for 5 hours at $550^{\circ} \mathrm{C}$ in a muffle furnace. The ash was taken up in $20 \% \mathrm{HCl}$ and the solution made up to $20 \mathrm{mls}$ with distilled water. Two hundred microliter aliquots from these solutions were further distilled to $10 \mathrm{mls}$ before analyzing for $\mathrm{Ca}, \mathrm{Mg}$ and $\mathrm{K}$ by atomic absorption spectrophotometry. Phosphorus, as molybdate-reactive $\mathrm{P}$ was measured by blue colorimetry at $730 \mathrm{~nm}$ using a spectrophotometer.

\section{Evaluation of root infection levels}

At seedling harvest, root tips $(1 \pm 0.2 \mathrm{~cm})$ were excised and cleared by autoclaving in $10 \% \mathrm{KOH}$ followed by staining in $0.05 \%$ tryphan blue, glycerol and lactic acid (1:1:1) solution. The frequency of mycorrhizal infection was noted per field (10 grids) for 10 fields, using the grid intersect method (Giovannetti and Mosse, 1980). To convert the data into percent infection, the frequency of infection as a fraction of the total number of grids observed was multiplied by 100 (Wamocho, 1998).

\section{Statistical analysis}

The data obtained was subjected to ANOVA, using Genstat software. All treatment means were tested for LSD and the means separated by Duncan's multiple range test (Little and Hills, 1978).

\section{RESULTS}

\section{Plant Height}

Arbuscular mycorrhizal papaya seedlings had higher plant height than non-mycorrhizal seedlings in both sterilized and unsterilized media. There was no significant difference in plant height between the mycorrhizal treatments, whether in sterilized or un-sterilized media. Non-mycorrhizal seedlings raised in sterilized media had significantly higher plant height than non-mycorrhizal seedlings raised in unsterilized media in papaya and lemon seedlings (Figure 1.0). 


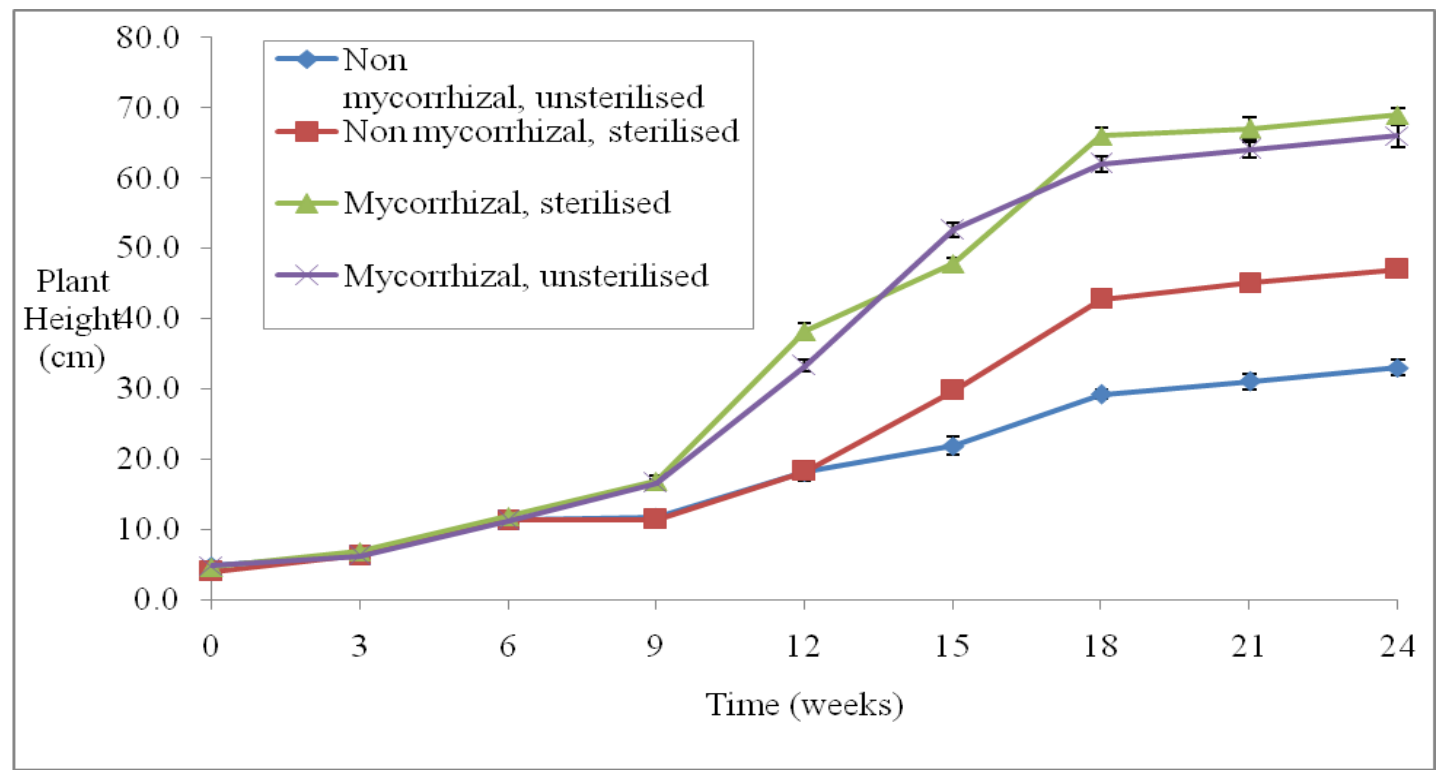

Fig.1: Effect of arbuscular mycorrhiza fungi and media condition on plant height (cm) of papaya (Carica papaya var mountain) seedlings

\section{Biomass measures}

Mycorrhizal papaya seedlings raised in both sterilized and unsterilized media had significantly higher stem and root fresh weight, root dry weight and leaf area than nonmycorrhizal plants under both sterilized and unsterilized media. There was no significant difference between all papaya treatments in leaf number, leaf fresh and dry weight and stem dry weight (Table 4.13). There was no significant difference in all parameters between mycorrhizal plants raised in either sterilized or unsterilized media. Non mycorrhizal plants raised in sterilized media had significantly higher root fresh and dry weight and leaf area compared to non-mycorrhizal plants raised in unsterilized media (Table 1.0).

Table 1.0 Effect of arbuscular mycorrhiza fungi and media condition on the leaf number, fresh and dry weight and leaf area of papaya (Carica papaya var mountain) seedlings

\begin{tabular}{|c|c|c|c|c|c|c|c|c|}
\hline \multirow[t]{2}{*}{ Treatments } & \multicolumn{3}{|c|}{ Leaf dry weight (g) } & \multicolumn{4}{|c|}{ Dry Weight (g) } & \multirow{2}{*}{$\begin{array}{l}\text { Leaf } \\
\text { Area } \\
(\mathrm{cm} 2)\end{array}$} \\
\hline & No. & Leaf & Stem & Root & Leaf & Stem & Root & \\
\hline Non mycorrhizal, unsterilised & $7.8 \mathrm{a}$ & $5.5 \mathrm{a}$ & $7.3 b$ & $13.6 \mathrm{c}$ & $1.2 \mathrm{a}$ & $0.8 \mathrm{a}$ & $4.2 \mathrm{c}$ & $117.4 \mathrm{c}$ \\
\hline Non mycorrhizal, sterilized & $8 \mathrm{a}$ & $5.6 \mathrm{a}$ & $7.3 b$ & $15.4 \mathrm{~b}$ & $1.3 \mathrm{a}$ & $0.8 \mathrm{a}$ & $4.7 \mathrm{~b}$ & $160.3 b$ \\
\hline Mycorrhizal, unsterilised & $7.6 \mathrm{a}$ & $5.8 \mathrm{a}$ & $7.9 \mathrm{a}$ & $19.9 \mathrm{a}$ & $1.2 \mathrm{a}$ & $0.8 \mathrm{a}$ & $6.2 \mathrm{a}$ & $226.1 \mathrm{a}$ \\
\hline Mycorrhizal, sterilised & $7.8 \mathrm{a}$ & $5.7 \mathrm{a}$ & $8.2 \mathrm{a}$ & $20.5 \mathrm{a}$ & $1.3 \mathrm{a}$ & $0.8 \mathrm{a}$ & $6.0 \mathrm{a}$ & $244.3 \mathrm{a}$ \\
\hline $\operatorname{LSD}(\mathrm{p} \leq 0.05)$ & 0.5 & 0.4 & 0.5 & 1.4 & 0.2 & 0.2 & 0.4 & 34.8 \\
\hline CV (\%) & 10 & 14.4 & 9.7 & 11.5 & 10.8 & 14.4 & 7.8 & 9.1 \\
\hline
\end{tabular}

${ }^{\mathrm{z} C}$ Column values followed by different letters are significantly different at $\mathrm{p}<0.05(\mathrm{n}=6)$ 


\section{Mycorrhizal Root Colonisation}

Mycorrhizal seedlings had significantly higher root colonisation than non-mycorrhizalseedlings. There was no significant difference in $\%$ root colonisation between mycorrhizal seedlings held in both sterilized and non-

Table 2.0: Effect of arbuscular mycorrhizafungi and planting media on the mycorrhizal root colonisation (\%) of papaya (Carica papaya var mountain) seedlings raised in sterilized and unsterilized media

\begin{tabular}{ll}
\hline Treatment & Infectivity (\%) \\
\hline Non Mycorrhizal, unsterilised media & $8.7 \pm 3.2$ \\
Non Mycorrhizal, sterilised media & 0 \\
Mycorrhizal, unsterilised media & $43.2 \pm 3.9$ \\
Mycorrhizal, sterilised media & $45.3 \pm 1.5$ \\
\hline
\end{tabular}

${ }^{z}$ Means $\pm \mathrm{SE}(\mathrm{N}=6)$

\section{Mycorrhiza Spore colonization}

At the start of the experiment, sterilized media did not have any mycorrhizal spores while unsterilized media had a low sterilized media. Non-mycorrhizal plants held in unsterilized media had low mycorrhizal colonisation \% while that held in sterilized media did not have any root colonisation (Table 2.0).

Table 3.0: Effect of media sterilization on mycorrhiza spore number at the beginning and at the end of the experiment period

\begin{tabular}{lll}
\hline Treatments & \multicolumn{2}{l}{ Spores per 25 gram soil sample } \\
& Beginning & End \\
\hline Mycorrhizal, sterilised media & 0 & $676 \pm 29$ \\
Mycorrhizal, unsterilised media & $68 \pm 8^{z}$ & $777 \pm 36$ \\
Non Mycorrhizal, sterilised media & 0 & 0 \\
Non Mycorrhizal, unsterilised media & $57 \pm 17$ & $158 \pm 16$ \\
\hline
\end{tabular}

${ }^{z}$ Means $\pm \mathrm{SE}(\overline{\mathrm{N}=6)}$

\section{Leaf Nutrient content}

Mycorrhizal seedlings had significantly higher $\mathrm{P}$ and $\mathrm{K} \%$ compared to non mycorrhizal seedlings. There was no

Table 4.0: Effect of arbuscular mycorrhiza fungi and planting media on the \% leaf nutrient content of papaya seedlings

\begin{tabular}{|c|c|c|c|c|c|}
\hline & $\mathrm{N}(\%)$ & $\mathrm{P}(\%)$ & K (\%) & $\mathrm{Ca}(\%)$ & $\operatorname{Mg}(\%)$ \\
\hline $\begin{array}{l}\text { Non Mycorrhizal, unsterilised } \\
\text { media }\end{array}$ & $1.9 \pm 0.1^{\mathrm{z}}$ & $0.2 \pm 0.1$ & $2.3 \pm 0.1$ & $1.9 \pm 0.2$ & $0.8 \pm 0.1$ \\
\hline Non Mycorrhizal, sterilised media & $1.9 \pm 0.1$ & $0.2 \pm 0.1$ & $2.2 \pm 0.2$ & $2.1 \pm 0.1$ & $0.9 \pm 0.1$ \\
\hline Mycorrhizal, unsterilised media & $2.0 \pm 0.1$ & $0.4 \pm 0.1$ & $2.9 \pm 0.1$ & $2.0 \pm 0.2$ & $0.9 \pm 0.1$ \\
\hline Mycorrhizal, sterilised media & $2.0 \pm 0.1$ & $0.4 \pm 0.1$ & $2.9 \pm 0.2$ & $2.1 \pm 0.1$ & $0.8 \pm 0.1$ \\
\hline
\end{tabular}

spore count. At the end of the experiment period, mycorrhizal inoculation caused a significantly higher spore count in both sterilized and unsterilized media (Table 3.0). 


\section{DISCUSSION}

Results from this study indicate that AM fungal inoculation improves growth of papaya seedlings. The improvement occurred through increase in plant height, leaf number and leaf area, increased biomass accumulation (fresh and dry weights) and improved nutrient uptake. Many researchers have also reported the benefits of arbuscular mycorrhiza on growth and biomass accumulation in plants. Mycorrhiza inoculation was found to increase the plant height, stem diameter and leaf number of sweet corn in USA (Tas, 2014). Similar observations were made by Al-Karaki (2013) in sour oranges and Suri and Choudhary (2013) in soybeans.

The improved performance of mycorrhizal seedlings can be attributed to improved efficiency of phosphorus uptake as evidenced by increased phosphorus accumulation in the leaves. In papaya study in India, leaf petiole of mycorrhizal plants recorded higher total phosphorus $(0.42-0.63 \%)$ as compared to control $(0.35 \%)$ plants (Kadhe and Rodrigues, 2009). A significant increase in shoot $P$ concentration was also observed when L. usitatissimum was inoculated with Glommus mosseae or G. intraradices and their combination (Rydlová et al., 2011).

In this study, mycorrhizal seedlings had greater root mass compared to un-inoculated seedlings, as indicated by greater root fresh weight. Likewise, the extent of mycorrhizal root infection was significantly greater in inoculated seedlings than in un-inoculated seedlings. It is expected that this greater mass of mycorrhizal roots corresponded to greater absorptive surface area for nutrients and water.

In this study potassium uptake was increased in papaya seedlings. This is consistent with pawpaw study in India which showed that total potassium content of leaf petiole was higher in mycorrhizal plants and ranged from 2.68 $4.39 \%$ as compared to non-mycorrhizal plants (2.26\%) (Kadhe and Rodrigues 2009). Uptake of $\mathrm{K}$ was also increased by AMF inoculation in cowpea and sorghum (Bagayoko et al., 2000). This can be attributed to greater soil exploration and increasing supply to host roots. Further increased $\mathrm{K}$ levels in mycorrhizal plants may be attributed to the fact that AM fungi binding soil particles to each other and to the roots, which is beneficial for the nutrient uptake (Estrada-Luna et al., 2000).

In the study in sand: soil media, mycorrhizal plants did not differ significantly, in all measured parameters, whether in sterilized or unsterilized media. This indicates that mycorrhizal inoculation played a greater role in the observed plant performance than media sterilization. Un-inoculated seedlings in this study performed poorly in both sterilized and un-sterilized media. However, un-inoculated seedlings held in sterilized media performed better that those held in unsterilized media. This could be attributed to elimination of all organisms in the media by sterilization. This can be an advantage through elimination of harmful micro-organisms in the media and could have contributed to the improved performance of un-inoculated seedlings in sterilized media.

On the other hand, lack of media sterilization can be an advantage because beneficial micro-organisms are not eliminated. In the un-sterilized seedlings, a small percentage of mycorrhizal root infection was observed. This was expected to have proved beneficial by antagonizing against harmful microbes in the media as reported by Elsen et al., (2003).

The presence of mycorrhizal infection in the roots of uninoculated seedlings raised in un-sterilized media suggests the availability of AM fungi in native soils in the tropics. In this study, unsterilized media had a small quantity of mycorrhizal spores at the beginning of the experiment. This is an indication of the low level of mycorrhization of native soils in Kenya and explains why non mycorrhizal seedlings performed poorly This confirms the report by Wamocho (1998) that in fruit orchards in Kenya, AM fungal spores and the mycorrhizal infection of fruit tree roots are low. Likewise, evidence from a survey of 41 tree species in five nurseries in Ethiopia and Somalia suggest that naturally mycorrhizal formation, even in unsterilized soils can be sparse (Michelson, 1992).

\section{REFERENCES}

[1] Al-Karaki, G.N. 2013. The effect of arbuscular mycorrhizal fungi on the establishment of sour orange (Citrus aurantium) under different levels of phosphorus. VII. International symposium on mineral nutrition of fruit crops book series. Acta Horticulturae, 984, 103-108.

[2] Bagayoko, M., George, E. Römheld, V. and Buerkert, A. (2000). Effects of mycorrhizae and phosphorus on growth and nutrient uptake of millet, cowpea and sorghum on a West African soil. Journal of Agricultural Science, 135: 399-407

[3] Bansal, M., Kukreja, K. and Dudeja, SS. 2012. Diversity of Arbuscular mycorrhizal fungi, prevalent in rhizosphere of different crops grown in the university farm. African Journal of Microbiology Research 6(21): 455-456.

[4] Cardoso, I.M. and Kuyper, TW. 2006. Mycorrhizas and tropical soil fertility: nutrient management in tropical 
agroecosystems. Agriculture Ecosystem Environment, 116: 72-84.

[5] Chebet D. Kariuki W., Wamocho L. and Rimberia F. 2020. Effect of Arbuscular mycorrhizal inoculation on growth, biochemical characteristics and nutrient uptake of passion fruit seedlings under flooding stress. International Journal of Agronomy and Agricultural Research (IJAAR) 16 (4): 24-31.

[6] Elsen, A., Baimey, H., Swennen, R. and De Waele D. 2003. Relative mycorrhizal dependency and mycorrhiza-nematode interaction in banana cultivars differing in nematode susceptibility. Plant and Soil 256: 303-313.

[7] Estrada, B.E., Aroca, R. Barea, JM. and Ruiz-Lozano, JM. (2013). Native arbuscular mycorrhizal fungi isolated from a saline habitat improved maize antioxidant systems and plant tolerance to salinity. Plant Science 201: 43-51.

[8] Giovannetti, M. and Mosse, B. 1980. An evaluation of techniques for measuring vesicular-arbuscular infection in roots. New Phytology, 84:489-500.

[9] Khade S.W and B. F. Rodrigues 2009. Studies on Effects of Arbuscular Mycorrhizal (Am.) Fungi on Mineral Nutrition of Carica papaya L. Notingham Botanicaland Horticulture Agrobot. Cluj, 37(1): 183-186.

[10] Little, T.M. and Hills, LJ. 1978. Agricultural Experimentation: Design and Analysis, New Jersey: John Wiley.

[11] Mason, P.A. and Wilson J. 1994. Harnessing symbiotic associations: vesicular-arbuscular mycorrhizas, p 165-175 In: Leakey, R.R.B., Newton, A.C. (Eds.), Tropical trees: potential for domestication and the rebuilding of forest resources. HMSO, London,.

[12] Michelson, A. 1992. Mycorrhiza and root nodulation in tree seedlings from five nurseries in Ethiopia and Somalia. For. Ecol. Manage. 48: 335-344.

[13] Othira, J.O., Omolo, JO. Kiruki, S. Onek LA. and Wachira, WC. 2014. Molecular diversity of arbuscular mycorrhizal fungi (AMF) in Lake Victoria Basin of Kenya. Journal of Ecology and Natural Environment, 6(4): 145-152

[14] Rydlová, J., Püschel, D. Sudová, R. Gryndler, M. Mikanová, $\mathrm{O}$ and Vosátka, M. 2011. Interaction of arbuscular mycorrhizal fungi and rhizobia: Effects on flax yield in spoilbank clay. Journal of Plant Nutrition and Soil Science, 174: 128-134.

[15] Suri, V.K and Choudhary, A.K. 2013. Effects of vesicular arbuscular mycorrhizae and applied phosphorus through targeted yield precision model on root morphology, productivity, and nutrient dynamics in soybean in an acid alfisol. Comm Soil Science Plant Analysis 17, 2587-2604.

[16] Tas, B. 2014. Effect of the Mycorrhiza Application on the Agronomical Properties of Sweet Corn Varieties. Journal of Agriculture and Allied Sciences 3(2): 41.47.

[17] Wamocho, L.S. 1998. Studies on the use of vesicular arbuscular mycorrhizal fungi for fruit production in Kenya.
$\mathrm{PhD}$ Thesis, Jomo Kenyatta University of Agriculture and Technology. 